\title{
Vocabulary Learning: A Critical Analysis of Techniques
}

Rebecca Oxford David Crookall

$\begin{array}{ll}\begin{array}{l}\text { This article evaluates more than a dozen } \\ \text { vocabulary learning techniques for stu- }\end{array} & \text { contextualizing, fully contextualizing, and } \\ \text { adaptable. Each technique is evaluated in } \\ \text { These techniques are divided into four } & \text { terms of underlying theoretical assump- } \\ \text { broad categories: decontextualizing, semi- } & \text { room implications are also offered. }\end{array}$

Given the difficulties of vocabulary learning in a second or foreign language (L2), along with the obvious necessity of trying to overcome them, one would expect that vocabulary instruction would be at the top of the agenda for language teachers. However, the opposite is often the case. Vocabulary is not explicitly taught in most language classes, and students are expected to "pick-up" vocabulary on their own without any guidance. Courses on reading, writing, speaking, listening, grammar, and culture are common in L2 programmes, but very few vocabulary courses exist. Many instances of so-called vocabulary instruction involve merely giving students lists of words to memorize or providing limited practice opportunities, with no further assistance to the often overwhelmed learner. Hague (1987) and Carter (1987) both decry the neglect of vocabulary instruction in L2 classes, and they also suggest a variety of possibilities for rectifying the situation.

In this article, our definition of "knowing an L2 word" involves not just the ability to recognize the word or to match it with its $\mathrm{Ll}$ counterpart, if such exists; knowing an L2 word also involves being able to use the L2 word communicatively in any of the four main language skills. To use Anderson's distinction (1980), our definition goes beyond merely "knowing that" (declarative knowledge of facts, definitions, or relationships) and includes "knowing how" (procedural knowledge, in this case the communicative use of $\mathrm{L} 2$ words).

This article describes a number of techniques by which vocabulary instruction has been handled, mishandled, or avoided almost entirely by L2 teachers. These techniques are classified into four groups: decontextualizing, semi-contextualizing, fully contextualizing, and adaptable. Decontextualizing techniques are those that remove the word as completely as possible from any communicative context that might help the learner 
remember and that might provide some notion as to how the word is actually used as a part of language. Semi-contextualizing techniques allow some degree of context but fall short of full contextuality; thus, new words may be linked with something that is meaningful to the learner, but they are not used as part of naturalistic communication. Fully contextualizing techniques are those that embed the new words in a more or less normal communicative context. These three types of techniques are not discrete but instead form a continuum of contextuality. The fourth classification, adaptable, refers to a technique that can reinforce other techniques at any part of the contextuality continuum.

Many of the techniques described here overlap with each other (e.g., visual imagery and semantic mapping), sharing a common base of theory and practice. For every technique, we will identify the underlying-and typically unarticulated-theoretical assumptions and provide a critical appraisal of the technique, based on a combination of existing research and our own judgment.

\section{Decontextualizing Techniques}

The three techniques that seem to be the most decontextualizing are word lists, flashcards, and conventional dictionary use. However, as will be shown, it is sometimes possible to modify these techniques to inject a bit of context.

\section{Word Lists}

One of the most prevalent means of trying to instill vocabulary in students is the use of word lists, a technique which does not necessarily involve any direct instruction by the teacher. Though we have not found any published, empirical data on the frequency of word lists in L2 textbooks and materials, our experience indicates that they are very common. In general, such lists are removed from any communicative context, that is, their relationship to the context in which the words will (one would hope) sooner or later be encountered is not directly shown. The assumptions that undergird this technique appear to be that learners do not need much, if any, context to learn vocabulary, and that rote memorization is perfectly adequate. L2 word lists are sometimes offered alone, without any native language (L1) equivalents. This kind of list can be termed an unpaired list. More often, lists include not just the L2 words to be memorized but also L1 equivalents. Such lists are called paired or pairedassociate word lists.

In an actual, university-level L2 class, students are told to memorize an alphabetical, unpaired, all-L2 list of approximately 1,500 common words, divided into smaller lists of several hundred words each, without the pro- 
vision of any context or L1 equivalents. Students look up the L1 meanings, memorize by rote (often by repeatedly copying the words), are tested at every class meeting, and usually forget the material after each test. More typically, however, students receive a paired list at the beginning or end of each chapter in a traditional L2 textbook. For instance, shown below is an excerpt from a paired list taken from a Russian advanced-level textbook (Liapunov, 1975, p. 3). The list appears just after a paragraph that (fortunately) contains the words in context, though any relation of the new words to the paragraph is not specifically mentioned. The excerpt below, which uses phonetic transcription but maintains the original format, is mostly L2-L1, but for two words (shkol'nik and uchitel'skaya) it becomes L2-L2 without explanation as to why. The use of hyphens is also not explained to the reader at the time the list appears.

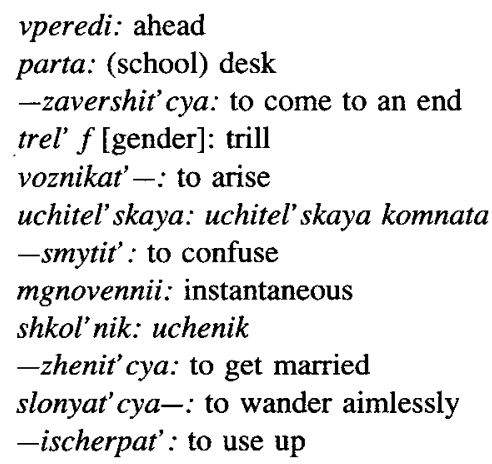

Learners are usually admonished to memorize paired lists like the one above, but with no training on how to achieve this feat. The small amount of context provided by typical dialogues or stories does not help much, and students usually focus on rote-memorizing the paired list rather than looking back at the slim context afforded by the passage. Paired lists are easier to learn if the student generates his or her own associations between the $\mathrm{L} 2$ and $\mathrm{L} 1$ equivalents (see the discussion of word association below), if the $\mathrm{L} 2$ and $\mathrm{L} 1$ words are obvious cognates, if the new $\mathrm{L} 2$ word is easily pronounceable and thus provides an acoustic hook for the learner, or if the L2 word represents a familiar part of speech (see Oxford, 1990b; Swaffar, 1988).

Many researchers state that paired lists are inadequate for vocabulary learning (Carrell, 1984; Hudson, 1982; Swaffar, 1988). In Carrell's words (p. 335), "merely presenting a list of new or unfamiliar vocabulary items to be encountered in a text, even with definitions appropriate to their use in that text, does not guarantee the induction of new schemata . . "Carter (1987) and Cohen and Aphek (1980) take a slightly different stand, suggesting that paired lists might be helpful for lower-level language learn- 
ers. In our own experience as language learners and teachers, paired lists have not been very useful. The degree of context offered by a paired list is minimal or even nil; and even if learners are able to memorize the L2-L1 pairs in a list, they might not be able to use the new words in any communicative way without further assistance.

\section{Flashcards}

Despite their decontextualizing nature, flashcards are very popular with students, especially for vocabulary self-testing. In our research using learning journals, in which students explain their L2 learning strategies, we have discovered that flashcards are among the most widely used vocabulary learning techniques. Commercial flashcards are available for many languages, including both traditionally taught languages like French, Spanish, and ESL and less common ones like Russian.

The flashcard technique involves at least three components: writing down (copying) the L2 word on the front of a card, writing the word's L1 meaning on the back, and then using the card to become familiar with the new word and its meaning. The flashcard thus represents a glorified L2-L1 word list broken into units, each containing one new word or expression in both $\mathrm{L} 2$ and $\mathrm{L} 1$ forms. The copying component (assuming that the flashcard is made by the student and not purchased as part of a set) might provide a small amount of kinesthetic benefit to some learners.

Unfortunately, we have not seen any empirical testing of the effectiveness of the flashcard technique. In our own assessment, the flashcard approach is limited in value for most students unless some contextualizing embellishments are added to the ordinary, decontextualizing flashcard. With creativity and thought on the part of the learner, flashcards can indeed be employed to provide greater context. For instance, learners can sort flashcards into piles representing different groups of words (e.g., nouns, adjectives, adverbs, verbs, prepositions; words that are already learned vs. words still needing to be learned; past tense forms vs. present tense forms). Learners can tape flashcards to particular objects like lamp, table, and chair signified by the words on the cards, thus providing a visual (and to a degree tactile) context. Visual context might also be added by taping relevant pictures to the cards. Learners can arrange flashcards on the floor in a kind of semantic map, with related words closer together and unrelated words farther apart. Finally, students can add context by writing the new words in complete, meaningful sentences on the cards.

\section{Dictionary Use}

Another typically decontextualizing technique is conventional "dictionary lookup". Underlying this technique is the idea that a reference book 
containing the meanings of new words helps the learner who would otherwise have no way of knowing what those words meant, and that the physical action of looking up the word somehow helps learners remember the meanings.

Some learners have been known to try to memorize the entire L2 dictionary, one page at a time. This particular use of the dictionary is analogous to memorizing infinitely long, decontextualized word lists. It has produced notable failures, except perhaps for those few learners with so-called photographic memories.

Looking up words while reading is a kind of dictionary use which some teachers feel promotes vocabulary growth and reading comprehension. Many students look up every single word they do not know and thus fail to use their existing ability to make inferences based on context. Swaffar (1988) cites several studies indicating that access to dictionaries or glosses fails to improve performance in reading; and it seems reasonable to infer from this that such practices would also fail to increase vocabulary. "Apparently, taking words from their context fails to promote the interactive process" between the learner and the text, and "glossing may have encouraged word for word reading with attendant detriment to conceptualizing" (Swaffar, p. 133). Relying on a dictionary as the primary way to increase vocabulary does not work because good readers do not think about the definition of individual words as they read (Hague, 1987). Another way of saying this is that mere definitional knowledge is not used in the process of comprehending text (Stahl, 1983).

Bilingual (L1-L2) dictionaries are typically used by beginning and intermediate language learners. Prolonged dependence on bilingual dictionaries retards development of proficiency in the new language (Baxter, 1980), probably by maintaining the conscious linkage between the L1 and the L2 and thus inhibiting the learner from thinking in the L2. Moreover, such dictionaries do not distinguish among shades of meaning in a way that would advance learners' comprehension.

The alternative to the bilingual dictionary is the monolingual (L2-L2) dictionary. Monolingual dictionaries are typically designed for native language users, but they are usually too difficult for beginning and intermediate learners of the new language. However, recent advances in lexicography have resulted in new kinds of monolingual dictionaries designed specifically for lower-level L2 learners rather than for native language users. For instance, some of the newer non-native English learners' monolingual dictionaries give detailed guidance on syntax, pronunciation, and usage restrictions caused by culture or style. Such dictionaries also provide definitions written in a simplified and controlled vocabulary, as well as specific examples of some words in context (Carter, 1987). Though most dictionaries (as described earlier) lack context and are ques- 
tionably helpful for remembering vocabulary, these new dictionaries provide a greater degree of context and might be more helpful to learners of all levels, though designed for lower levels.

\section{Semi-Contextualizing Techniques}

A number of semi-contextualizing techniques exist for learning L2 vocabulary: words grouping, word or concept association, visual imagery, aural imagery, keyword, physical response, physical sensation, and semantic mapping. Some of the context comes from associations with other words or word-sounds (e.g., in word grouping, word or concept association, and to a degree in aural imagery), while in other instances the context is more extra-linguistic (e.g., in visual imagery, physical response, and physical sensation). Sometimes the context provided by multiple means, as in semantic mapping and keyword.

\section{Word Grouping}

The technique of word grouping involves dividing a longer word list into new, shorter lists by classifying or reclassifying the target language terms according to one or more important attributes. In this way, some degree of context is created. Word grouping establishes new groups or sets of words which hang together because of some common theme or characteristic, unlike the generally unorganized, decontextualizing word lists described earlier. The theory seemingly underlying this technique is that grouping makes vocabulary learning easier by reducing the number of discrete elements and-in optimal situations-linking new, target language material with concepts that the learner already knows in his or her native language.

Groups can be based on type of word (e.g., all nouns or adjectives), grammatical form (e.g., irregular verbs of a certain kind), topic (e.g., words about weather), practical function (e.g., terms for things that make a car work), language function (e.g., apology, request, demand), similarity (e.g., warm, hot, tepid, tropical), dissimilarity or opposition (e.g., friendly/unfriendly), the way one feels about something (e.g., like, dislike), and so on. Language textbooks sometimes group new vocabulary into thematic sets; and word grouping is often used by teachers in the language classroom.

Here is a more detailed example of word grouping. A learner of French groups together in a specialized word list some words related to computers: l'informatique (computer science), l'ordinateur (computer), le moniteur (monitor), l'ecran (computer screen), le clavier (keyboard), la puce (chip, literally flea), l'unite central (central processing unit), and les touches 
(keys on the keyboard). Additional words can be added to this group as the learner progresses in French.

Crow's "semantic fields" approach involves grouping words according to their semantic relationships and stresses general rather than specific meanings. For instance, students are rewarded for knowing that ugly and uncomely convey similar meanings, even though they may not know which one of these best describes personal appearance, weather, or disposition (Swaffar, 1988). In a recent study, semantic field recognition among advanced ESL students developed receptive control of twice as many words as did list- and synonym-learning techniques (Crow \& Quigley, 1985).

A technique sometimes known as "semantic features analysis", "semantic grids", or "componential analysis" (Hague, 1987; Carter, 1987; Harvey, 1983; Stieglitz, 1983; Van Buren, 1975) is a special kind of word grouping. This technique requires students to list across the top of a grid a set of words, such as man, woman, child, dog, landscape, house, furniture, dress, present, and voice; and then list a set of attributes (handsome, pretty, charming, lovely) down the side of the grid. Inside the grid, students rate each word (with a + or a - ) according to the presence or absence of each attribute, thus creating a matrix of ratings and in effect forming groups of words for each attribute. Such grids, while potentially very useful for upper intermediate and advanced learners who already have a fairly good stock of vocabulary, have been criticized as suggesting a static, prescriptive model for teachers and learners; as not being particularly natural; and as difficult because learners might not have encountered the words in sufficiently varied contexts to be able to rate semantic features appropriately (Porter \& Williams, 1983). Despite such potential drawbacks, semantic grids can indeed be useful. Where semantic grids might indeed be most valuable is for helping intermediate and advanced learners learn to make distinctions within semantic fields (see above).

The power of word grouping is often enhanced by labeling the groups, as in Weather Words, Girl's Clothing Items, Russian Verbs of Motion, and Helpful Vocabulary for Going to the Store (Oxford, 1990b). Mechanical aids can also be used, such as grouping certain kinds of words in one section of a language learning notebook. A number of games useful for word grouping are found in Maley and Duff (1982), as well as in the many other compilations of games for language learning (see Crookall, 1990). See also visual imagery and semantic mapping (below) for additional grouping ideas.

Word grouping, with all its benefits, is nevertheless limited in one sense: it does not usually show the specific relationships among the words in a group. For instance, a group of Car Words might include carburetor, 
gas cap, crank shaft, battery, hood, seat, stick shift, oil gauge, and so on, with no indication of how each of these specifically relates to the others in terms of function, form, or placement in a car.

\section{Word or Concept Association}

Word association and concept association tasks, sometimes known as "elaboration," involve making associations between the new word or concept and the words or concepts already in the learner's memory, thus creating some context for the learner. The theory is that as long as these associations are meaningful to the learner, they will strengthen the learner's existing schemata and at the same time make the new word more accessible.

The associations can be simple or complex, ordinary or strange, as long as they are significant to the learner. The learner of English may associate bread with butter using semantic, auditory, and possibly visual associations. Likewise, the learner of German might find it useful to associate the English words wise and shaft with the new word to be remembered, Wissenschaft (knowledge). Associations can also be in the form of a multipart development, moving from one concept to another, such as schoolbook-paper-tree-country-earth (Wright, 1987, p. 53).

Word association can involve making links among items listed in a finite group of new words, thus providing the basis for subdividing and rearranging the group based on certain associative attributes, such as partwhole. Alternatively, word association can reflect more divergent thinking, in which the learner creates new associations between a new word, e.g., tyrannical, and any personally meaningful word or concept which is not in the list of new words, e.g., my mean old Aunt Louise.

Word association and concept association tasks, in which the teacher asks the students to make new associations, can be used for diagnosis of what students already know and what they need to learn. Students' initial associations might be about synonyms, antonyms, reverses, attributes, definitions, superordinates, subordinates, personal experiences, sound similarities, and so on (Carrell, 1984). Cohen and Aphek (1980) studied the use of mnemonic associations and found that although these devices sometimes slowed down or limited possible meanings, they made vocabulary learning easier and longer-lasting.

\section{Visual Imagery}

Visual imagery is a very useful semi-contextualizing aid for learning L2 vocabulary. The use of visual imagery for vocabulary learning is based on making associations between a picture and a word. The theory on which 
this technique is founded is that most learners are capable of associating new information to concepts in memory by means of meaningful visual images, and that visual images make learning more efficient. Visual imagery is known to help learners package information more efficiently than they could if using just words alone (Bower, 1970; Higbee, 1979; Nyikos, 1987; Shephard, 1967). Moreover, the pictorial-verbal combination involves many parts of the brain, thus providing greater cognitive power. A large number of learners in our culture are primarily visual learners (Dunn \& Dunn, 1972), and about $94 \%$ of all people are at least moderately good at using visual imagery (Goleman, 1986), though they do not always apply it to learning.

People are used to the linkage between verbal and visual symbols, such as found in a whole array of public signs and notices (e.g., no-smoking signs on airplanes and stop signs and yield signs on highways). These familiar verbal-visual links can help L2 learners. Another kind of visual image useful to L2 learners is a mental image or a drawing of an object related to a new L2 word, such as a house full of money for the term tax shelter. Learners can use visual imagery by making their own drawings or sketches of words or phrases (especially helpful for prepositions like above, over, under, and so on). Another aid is to visualize a set of locations (possibly the rooms in one's house or apartment), to associate each location with a specific word or expression, and then to take a mental walk from place to place - an ancient Greek technique for remembering a word sequence or segments of a long speech. Visual imagery can also involve a large and emphatic mental representation of the letters of a word, such as the German Gesellschaft.

Word grouping (described above) can be embellished by visual effects, such as colour-coding different groups, e.g., in using blue for all the masculine nouns, pronouns, and adjectives; pink for the feminine ones; and yellow for the neutral ones (see Nyikos, 1987 for colour ideas). Different visual images can be assigned to feminine and masculine nouns: for instance, one learner uses the technique of mentally visualizing long, blonde hair draped over feminine nouns like la table, the table, and muscles bulging from masculine nouns such as le livre, the book (Talbott, 1989). Even abstract words can be remembered through visual imagery; learners simply associate such words with a visual symbol or a picture of a concrete object. For instance, the abstract word evil can be remembered by a learner of English through an image or symbol, such as a bloody knife, associated with the word evil. The abstract concept of danger is commonly visualized by means of a picture of a skull and crossbones.

In spite of the advantages of visual imagery, particularly its ability to provide a needed degree of context for new words, most language teachers 
do not think to encourage students to apply visual imaging skills to L2 vocabulary learning. Visual imagery is a resource that deserves further tapping.

\section{Aural Imagery}

L2 words can be represented in memory by using aural imagery rather than visual imagery. As with visual imagery, aural imagery provides a form of semi-context for the learner and a link with what the learner already knows. The theory underlying this technique is that aural imagery makes verbal learning more efficient through associating new sounds with existing, sound-related schemata.

For instance, learners can link an L2 word, such as German Katze or Russian kot, with the familiar L1 word, cat. Not only do all these sound similar, but they have similar meanings. Words which mean different things but which can be acoustically (and possibly semantically) linked can also be useful, e.g., Russian brat (brother) and English brat (annoying person). In addition, learners can use phonetic spelling, accent marks, or rhymes to remember a new target language word.

However, a large number of learners, with the proportion depending chiefly upon cultural expectations and experience, are not primarily aural learners but rather visual learners or else "combination" learners who prefer a mixture of sensory media (Dunn \& Dunn, 1972). Orality was once the prevalent mode of communication and was related to oral-aural styles of learning. However, the "technologizing of the word" (Ong, 1982) through writing and printing has made learning much less oral-aural and much more reliant on the visual mode. Even the current electronic media are fundamentally literate and visual, says Ong; for instance, TV programmes, movies, and computer games, though delivered with an obvious oral-aural component, are typically based on scripts and programming that have been visibly written, and the visual image seems to be primary in the delivery. It is no wonder that the Audiolingual Method was not consistently successful, because it tried to make acoustic links while-at least in lower levels-largely ignoring the printed word as an important medium of presenting language. In our culture the use of purely aural imagery is not likely to be as popular or effective as visual imagery or a mixture of visual-aural imagery modes.

\section{Keyword}

The keyword technique is an example of a combination of two semi-contextualizing modes, aural imagery and visual imagery (see above). The basic theory of this technique is that remembering an L2 word can be 
facilitated by using auditory and visual links together, thus more strongly tying the new words to existing schemata.

The first step is to identify a familiar word in one's own language that sounds like the new word; this is the auditory link. The second step is to generate a visual image of some relationship between the new word and a familiar one; this is the visual link. Both links must be meaningful to the learner. For example, to learn the new French word potage (soup), the English speaker associates it with a pot and then mentally pictures a pot full of potage.

A significant amount of research supports laboratory experiments in foreign language vocabulary learning using the keyword technique (see Levin, 1981; also Oxford \& Crookall, 1989). Commercially available language learning systems (e.g., the Link Word System) have been built on the keyword technique (see Gruneberg, 1987). One caution is that some of the auditory links in the keyword technique might not be perfect; that is, the new word in the target language might not sound exactly like the familiar word in one's own language. Despite the successes of the keyword technique, it appears to be little used in language classrooms.

\section{Physical Response}

Use of physical response involves physically acting out a new L2 expression, thus providing a degree of context for that expression. The Total Physical Response (TPR) technique (see Asher, 1966) embodies and popularizes this technique for $\mathrm{L} 2$ learning. The theory undergirding this technique seems to be that language can best be learned when words are linked with physical movement, thus activating different parts of the brain and stimulating the learner's schemata in multiple ways.

At first, TPR requires the teacher to give commands (e.g., going out, walking to the blackboard, tapping someone on the head), which the students must follow by acting them out, at first without any L2 production on the students' part. Later, as students become more proficient, the teacher's commands become more elaborate: Take the pencil, go to the pencil sharpener, and sharpen the pencil. Go back to your desk, sit down, and write your name with the pencil. After you have written your name, then give the pencil to Bill. Still later, when learners are increasingly skilled in the L2, they begin to speak and can then give commands to their teacher or their peers.

One problem with TPR is that it does not handle abstract nouns well. An artificial and outright silly use of abstract nouns in TPR (as pointed out by Omaggio, 1986) is to write out such nouns on slips of paper and to incorporate them into commands, e.g., Si-Ying, pick up justice, and hand it to Miko. Another serious limitation is that TPR commands cannot 
include the full range of language functions necessary for intermediate or advanced L2 proficiency. Nevertheless, TPR has proven to be a successful, though rather limited, technique for lower-level students and has enlivened many a language classroom. Its combination of motion and verbal input might be particularly useful for those students who learn best kinesthetically.

\section{Physical Sensation}

Another potentially useful L2 vocabulary learning technique that we have not seen described by others is physical sensation (Oxford, 1990b). This technique provides a small amount of context in terms of a physical association with a new word. This technique is related to biofeedback, in which awareness of highly specific physical sensations (e.g., warm/coolness, smoothness/roughness) help people monitor and sometimes even alter their own mental or physical state. An example of the physical sensation technique is as follows. A learner trains himself or herself to have an aversive feeling of prickliness when considering words representing things $s$ / he does not like (e.g., the L2 equivalents of punishment, deceit, poverty, examination, toil, war, fighting, ugliness, fraud) and a feeling of peaceful calm when considering L2 words representing enjoyable things (e.g., happiness, friend, party, food, beauty, honesty, truth). Physical sensation could also be creatively used to remember the gender of L2 words. Another use of physical sensation might be for remembering adjectives of shape, size, or temperature, such as round, big, or hot. This technique has not been empirically tested, though it might seem to offer promise.

\section{Semantic Mapping}

Semantic mapping, a potentially valuable tool for learning L2 vocabulary, can be conceived as a single technique, although it actually draws upon three of the techniques named above: word grouping, word association, and visual imagery. It is therefore the most sophisticated of the semi-contextualizing techniques. This technique involves making a graphic arrangement of words in terms of their semantic relationships and attributes. The arrangement clearly offers a degree of context for understanding and remembering new words. The key concept is highlighted or centralized, and it is linked with subsidiary concepts, attributes, and so on by means of lines or arrows showing relationships.

One possible theory behind semantic mapping might be that the map visually represents the ways in which new words fit into a learner's existing schemata; and most certainly, the map can be a highly useful visual display of the ways in which ideas are related to each other within a text 
(Hague, 1987; Carrell, 1984). Unlike word grouping, semantic mapping not only puts words into categories but also shows the conceptual links or paths among the words. Semantic mapping can be used to improve both comprehension and retention of L2 information, and as a diagnostic prereading activity.

An example of L2 semantic mapping is found in Figure 1, in which Russian words (and their English equivalents) related to common classroom objects and people are shown. In a semantic map, only the L2 words need be shown, but we have given the L1 equivalents for the benefit of readers who do not know any Russian.

Figure 1. Semantic Map for Russian Words Concerning Classroom Objects and People

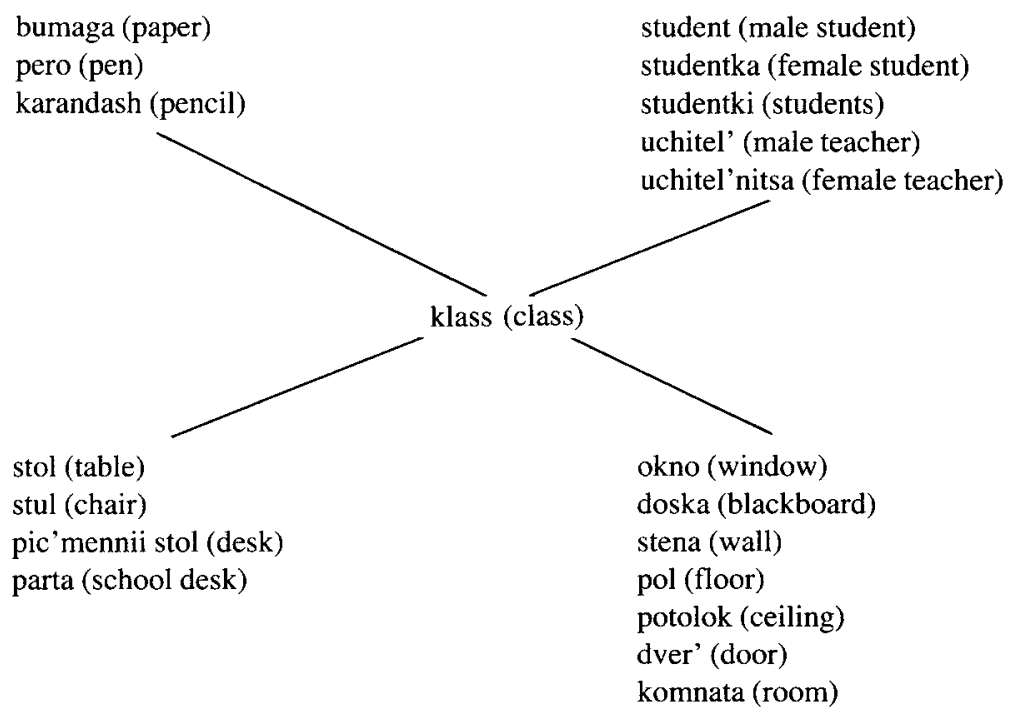

We have summarized Hague's six steps for using semantic mapping as follows:

1. Write the target word on the chalkboard or transparency.

2. Have the class members brainstorm words related to the topic.

3. Write/list the words by categories in the form of a map.

4. Have the students provide labels for each category (optional).

5. Discuss the words on the semantic map. Students should be encouraged to discover how the concepts are related to each other.

6. Revise the map after discussion, if necessary. Add new concepts to the map as the lesson progresses. 
Carrell (1984) suggests that in the discussion phase (listed as Step 5 above), students' networks of associations are elaborated. Discussions of the semantic map encourage students to make analogies, comparisons, or metaphors to bridge the gap between what they already know about a concept and what they need to know. During the discussions, the teacher provides additional examples of what the new concept includes and does not include (an activity related to semantic features analysis).

Semantic mapping has many possible uses. Novak and Gowin (1984), applying their own term of conceptual mapping, have used the technique of semantic mapping for decades as the basis of an instructional system which focuses on "learning how to learn." Wright (1987) demonstrates the use of semantic mapping for taking notes on a reading passage. BrownAzarowicz, Stannard, and Goldin (1986) show the usefulness of semantic mapping, which they call a concept tree, for memorizing foreign language vocabulary. Any language curriculum should have a general programme of concept and vocabulary development, a programme not restricted to teaching new labels for old concepts but also teaching new concepts and helping students make appropriate links between oral and written labels (Carrell, 1984). Semantic mapping could easily become part of such a programme. Despite its promise, semantic mapping is still relatively unknown among language teachers. It certainly warrants more attention and more study of its cognitive characteristics (see Oxford \& Holland, forthcoming).

\section{Fully Contextualizing Techniques}

Practicing the four language skills of reading, listening, speaking, and writing can provide full context. At first blush, we would expect that practice is at the very pinnacle of L2 vocabulary learning techniques, and that nothing else might be necessary. Indeed, the theory exists that L2 practice, particularly naturalistic practice, is automatically equivalent to vocabulary learning. The most explicit statement of this theory has occurred in the reading area, but the assumption is also implicit in discussions of the other three skills. The difficulty with this notion is that practice alone is not sufficient for vocabulary growth. Also required is the learner's genuine personal interest in challenging tasks and activities that create the need for expansion of vocabulary, along with specific vocabulary learning techniques keyed to the person's needs and learning style.

\section{Reading and Listening Practice}

L2 reading practice can involve a vast variety of material: comic strips, advertisements, letters, articles, stories, newspapers, magazines, books, jigsaw reading exercises (Crookall \& Watson, 1985), and so on. Some 
theorists believe that through reading practice students will absorb and retain vocabulary by osmosis, i.e., merely by reading words in context without any special training in either vocabulary learning or reading. For instance, Krashen (1982) recommends that students do "massive amounts of reading for pleasure," which he suggests will automatically increase their vocabulary (Krashen, 1988). He concedes that it is indeed possible to make small gains in vocabulary knowledge through large amounts of special vocabulary learning effort, but says that this is not worth the time involved and that better results can come through massive reading alone.

However, though learners might be able to infer the meaning of a word read in context, this does not guarantee that the word is completely learned or known. Receptive comprehension of a new word is fostered by massive reading, but the capability to produce that word is by no means ensured by this technique (Carrell, 1984; Carter, 1987). Even encountering a word in reading numerous times, as in "narrow reading" (Krashen, 1981), might not be enough to allow use of the word in later production.

Osmosis theories work no better in listening than in reading. Repeated L2 listening practice (as in the excellent exercises offered by Ur, 1984) cannot be the only avenue for building vocabulary knowledge. Recognizing a new L2 word or being able to guess the meaning of an unknown L2 word in a flow of speech does not imply that the student has actually learned the word; often, as in reading, an unfamiliar word is merely skipped over when the context provides sufficient clues about the meaning of the whole sentence. Even repeated exposure to the word in various contexts might not necessarily enable the learner to recognize or comprehend the word each time, and it is definitely not tantamount to productive knowledge.

\section{Speaking and Writing Practice}

Some distinctions between productive and receptive vocabulary knowledge may be important here. Spoken vocabulary is often smaller than written vocabulary, which is in turn generally smaller than receptive (reading and listening) vocabulary. This fact coincides with the truism that, for many learners, proficiency is more difficult to reach and sustain in speaking than in writing, and more difficult in writing than in reading and listening.

Some L2 teachers may feel that students learn vocabulary most effectively by practicing it through speaking or writing. Sufficient exposure to the new target language word in meaningful, communicative, oral or written contexts is no doubt essential. Simulation/gaming, small group discussions, project work, and other communicative techniques provide naturalistic, motivating practice in speaking and writing (Jones, 1982; 
Crookall \& Oxford, 1990; Crookall \& Saunders, 1989; Saunders \& Crookall, 1985). The ability to productively use new vocabulary is extremely important and recently been highlighted through the communicative approach and the proficiency movement (Oxford, Lavine, \& Crookall, 1989).

Production practice can help learners expand their vocabulary in several ways. First, such practice forces the learner to access relevant schemata and put them rapidly into production. Second, for the alert learner such practice provides many opportunities for feedback about whether the learner is using the new word correctly and whether the new word carries a particular nuance or connotation. This feedback gradually helps to shape and reshape the learner's existing schemata related to the new word. However, production practice cannot be the totality of vocabulary learning; it can only tap those words which are already in the learner's existing schemata. Techniques for getting new L2 words into memory (linking new information with existing schemata) and for recalling them when needed are required before the words become accessible for productive use.

\section{Adaptable Technique: Structured Reviewing}

Structured reviewing is an adaptable technique that can be used to reinforce any of the other techniques named above at any part of the contextuality continuum: decontextualizing, semi-contextualizing, and fully contextualizing. Structured reviewing creates a structured schedule for reviewing new words, no matter which particular technique is being used by the learner.

The technique of structured reviewing entails going back over $L 2$ vocabulary at different intervals, at first close together and then increasingly far apart. For instance, the learner practices vocabulary words several times, then waits 15 minutes before practicing them again, and practices them an hour later, three hours later, the next day, two days later, the following week, and so on until the material becomes automatic (or "overlearned"). In this way, the learner keeps spiraling back to these particular words, even though he or she is encountering other words in the meantime. Naturally, the duration needed to make the words automatic depends on the difficulty of the words, the degree of context, and other factors.

Structured reviewing is scientifically based on memory principles, which highlight the importance of primacy, recency, duration, spacing, pacing, and linking, as noted by Stevick (1976). Oxford (1990b) and Brown-Azarowicz et al. (1986) present illustrations of structured reviewing for L2 vocabulary expansion. Though structured reviewing is very powerful, L2 textbooks typically fail to make any overt suggestions to 
learners about this technique. Moreover, many such textbooks do not present L2 words in a consciously spiraled way that would implicitly lead learners to use structured reviewing. Some of the best teachers tend to spiral back over previously learned L2 words to help their students review, but many teachers simply drop previously covered words as they move on to new ones. Structured reviewing is thus an important vocabulary learning technique that has not been used to its full potential.

\section{Classroom Implications}

Vocabulary learning is very important for developing L2 proficiency, but the difficulty of the task sometimes makes it foreboding for learners. Many techniques have been analyzed in this article in terms of their theoretical bases and practical utility for vocabulary learning (see also Oxford \& Crookall, 1990). Several classroom implications arise from the foregoing discussion.

\section{Appropriateness of L2 Vocabulary Techniques to Learning Style}

Teachers should pay attention to the ways in which learning style preferences might affect vocabulary learning. Cultural and ethnic differences in learning styles may be very important and should be considered in understanding how people learn vocabulary. Sensory preferences, such as visual, aural, tactile, and kinesthetic, should be assessed (see Reid, 1987). Learners with a visual style are likely to enjoy visual imagery and semantic mapping, while aural learners might prefer aural imagery and the keyword, and kinesthetic-tactile learners might opt for physical response or physical sensation. Other aspects of learning style, such as analytic vs. leveling, also deserve attention vis-a-vis vocabulary learning (see Oxford, 1990a).

Learning style should be investigated in systematic, classroom-oriented research, the results of which are accessible to both teachers and students. A number of very practical learning style inventories, easily administered by means of paper and pencil, are available to measure many different aspects or dimensions of style; these are listed and described elsewhere (see, e.g., Oxford, 1990a; Reid, 1987; Myers, 1962; Ehrman \& Oxford, 1988, 1989; Oxford \& Ehrman, 1989; Kolb, 1983; Parry, 1984). The 4MAT System (McCarthy, 1987), based on Kolb's learning style theory, has been widely used to adapt curricula to differences in learning styles.

Whenever possible, the type of vocabulary instruction should be consciously matched to learners' style preferences. This means that teachers should teach students to use various kinds of techniques, so that all learners, regardless of preferred style, will be able to learn vocabulary more efficiently. 


\section{Reassessment of Decontextualizing Techniques}

The second implication is that teachers should carefully reassess the utility of commonly employed, decontextualizing techniques such as word lists, flashcards, and conventional dictionary use. This reassessment can be done by using the evaluative information in this article and by seeking out other sources from the reference list and from other bibliographies. We should not unquestioningly accept any traditional or well-known technique, no matter how frequently used. Part of the reassessment might be a consideration of ways in which these popular but limited techniques might be modified to become more contextual. Some preliminary suggestions have been given in this article.

\section{Beyond Practice}

The third implication is that high-context practice in the language skills of reading, listening, speaking, and writing is necessary but certainly not sufficient for the steady growth of $\mathrm{L} 2$ vocabulary knowledge. Such practice is useful but cannot be considered the sole vehicle for vocabulary learning. Even when multiple contacts with the same word are provided in reading and listening practice situations, vocabulary learning by osmosis is neither adequate nor efficient for the typical student. Likewise, production practice through speaking and writing can only operate when relevant schemata already exist and are ripe for action and expansion. Therefore, L2 practice must be supplemented by a range of additional techniques for vocabulary learning. These might include word grouping, word association, semantic mapping, structured reviewing, and any of the other techniques which have been evaluated positively in this article.

\section{Strategy Training}

The final implication is that teachers should become familiar with a variety of vocabulary instruction tools and should train their students to use them. Such training can best be accomplished by weaving it into normal classroom activities. A training sequence relevant to vocabulary learning techniques, as well as to other types of language learning tools, is as follows: (1) determine learners' needs by exploring expectations and current vocabulary learning techniques; (2) choose relevant techniques to teach; (3) find ways to integrate these techniques into everyday language instruction; (4) consider issues of student motivation toward and anxieties concerning learning L2 vocabulary; (5) prepare materials and activities; (6) conduct completely informed training, in which learners are explicitly told how to use a particular technique to learn a given word, how to evaluate the success of the technique, and how to transfer it to a new word 
or set of words; (7) evaluate the training in terms of improvement in vocabulary learning, attitudes, and self-confidence; and (8) revise the training as needed. See Oxford (1990b) for further details.

In conclusion, greater attention to vocabulary learning by teachers and students will result in greater overall language progress. Powerful techniques for vocabulary growth should be explored and exploited, so that language learners will be able to make their way more easily to their proficiency goals.

\section{ACKNOWLEDGMENTS}

The research for a report on which some of this paper is based was supported by funding from the Army Research Institute, by means of a contract from the Office of Personnel Management to Advanced Technology Inc. Special thanks go to Joseph Psotka, Melissa Holland, Merryanna Swartz, and Frank O'Mara. In addition, we want to thank the editors of this journal and the anonymous reviewers for their very helpful comments.

\section{REFERENCES}

Anderson, J. R. (1980). Cognitive psychology and its implications. San Francisco: Freeman.

Asher, J. J. (1966). The strategy of the total physical response: An application to learning Russian. International Review of Applied Linguistics, 3, 291-300.

Baxter, J. (1980). The dictionary and vocabulary behavior: A single word or a handful? TESOL Quarterly, 114 (3), 325-336.

Bower, C. H. (1970). Analysis of a mnemonic device. American Scientist, 58, 496-510.

Brown-Azarowicz, M., C. Stannard, \& M. Goldin. (1986). Yes! You can learn a foreign language. Lincolnwood, IL: National Textbook Co.

Carrell, R. (1984). Schema theory and ESL reading: Classroom implications and applications. Modern Language Journal, 68 (4), 332-343.

Carter, R. (1987). Vocabulary and second/foreign language teaching. Language Teaching, 20 (1), 3-16.

Cohen, A., \& E. Aphek. (1980). Retention of second-language vocabulary over time: Investigating the role of mnemonic associations. System, 8 (3), 221-235.

Crookall, D. (1990). Sources and resources. Language learning through simulation/gaming. Ed. D. Crookall \& R. Oxford. New York: Newbury House/ Harper \& Row.

Crookall, D., \& R. Oxford. (1990). Language learning through simulation/gaming New York: Newbury House/Harper \& Row. 
Crookall, D., \& D. Saunders. (1989). Communication and simulation: From two fields to one theme. Clevedon and Philadelphia: Multilingual Matters.

Crookall, D., \& R. Watson. (1985) Some applied and theoretical perspectives on a jigsaw reading exercise. International Review of Applied Linguistics 69, 43 79 .

Crow, J. T. \& J. Quigley. (1985). A semantic field approach to passive vocabulary for reading comprehension. TESOL Quarterly, 19, 497-513.

Dunn, R. S. \& K. J. Dunn. (1972). Learning styles/teaching styles: Should they . . . can they . . . be matched? Educational Leadership, 36, 238-244.

Ehrman, M. \& R. Oxford. (1988). Ants and grasshoppers, badgers and butterflies: Quantitative and qualitative exploration of adult language learning styles and strategies. Presentation at the Symposium on Research Perspectives on Adult Language Learning and Acquisition, The Ohio State University, Columbus, $\mathrm{OH}$.

Ehrman, M. \& R. Oxford. (1989). Effects of sex differences, career choice, and psychological type on adult language learning strategies. Modern Language Journal 73 (1), 1-13.

Coleman, D. (Aug. 12, 1986). Mental images: New research helps clarify their role. The New York Times, pp. C1, C6.

Gruneberg, M. (1987). The Link Word Language System: Spanish. London: Corgi.

Hague, S. A. (1987). Vocabulary learning: The use of grids. English Language Teaching Journal, 37 (3), 243-246.

Higbee, K. L. (1979). Recent research on visual mnemonics: Historical roots and educational fruits. Review of Educational Research, 49 (4), 611-629.

Hudson, T. (1982). The affects of induced schemata on the 'short-circuit' in L2 reading performance: Non-decoding factors in L2 reading performance. Language Learning, 32; 1-31.

Jones, K. (1982). Simulations in language teaching, Cambridge: Cambridge University Press.

Kolb, D. A. (1983). Experiential learning: Experience as the source of learning and development. Englewood Cliffs, NJ: Prentice Hall.

Krashen, S. (1981). Second language learning and second language acquisition. Oxford: Pergamon.

Krashen, S. (1982). Principles and practices in second language acquisition, Oxford, Pergamon.

Krashen, S. (1988). Research on second language spelling and vocabulary acquisition. Presentation at the Symposium on Research Perspectives on Adult Language Learning and Acquisition, The Ohio State University, Columbus, $\mathrm{OH}$. 
Levin, J. R. (1981). The mnemonic 80's: Keywords in the classroom. Educational Psychologist, 16, 65-82.

Liapunov, M. (1975). Russian advanced level ALM. 2nd ed. New York: Harcourt Brace Jovanovich.

Maley, A. \& A. Duff. (1982). Drama techniques in language teaching: A resource book of communication activities for language teachers. 2nd ed. Cambridge: Cambridge University Press.

McCarthy, B. (1987). The 4Mat System: Teaching to learning styles with right/left mode techniques. Barrington, IL: EXCEL.

Myers, I. (1962). The Myers-Briggs Type Indicator. Palo Alto, CA: Consulting Psychologists Press.

Novak, D., \& D. B. Gowin. (1984). Learning how to learn. Cambridge: Cambridge University Press.

Nyikos, M. (1987). The use of color and imagery as associative strategies for the retention of lexical items in German. Unpublished dissertation, Purdue University, West Lafayette, IN.

Omaggio, A. (1986). Teaching language in context: Proficiency-oriented instruction. Boston: Heinle \& Heinle.

Ong, W. J. (1982). Orality and literacy: The technologizing of the word. London: Methuen.

Oxford, R. (1990a). Language learning strategies and beyond: A look at strategies in the context of styles. Shifting the instructional focus to the learner. Ed. S. S. Magnan. Middlebury, VT: Northeast Conference.

Oxford, R. (1990b). Language learning strategies: What every teacher should know. New York: Newbury House/Harper \& Row.

Oxford, R. \& D. Crookall. (1989). Research on language learning strategies: Methods, findings, and instructional issues. Modern Language Journal, 71 (4).

Oxford, R. \& D. Crookall. (1990). Issues and problems in L2 vocabulary learning. Submitted.

Oxford, R., \& M. Holland. (Forthcoming). Drowning in a sea of words: Semantic mapping as a possible lifeline.

Oxford, R., R. Lavine, \& D. Crookall. (1989). Language learning strategies, the communicative approach, and their classroom implications. Foreign Language Annals, 22 (1), 29-39.

Parry, T. S. (1984). The relationship of selected dimensions of learner cognitive style, aptitude, and general intelligence factors to selected foreign language proficiency tasks of second-year students of Spanish at the secondary level. Unpublished dissertation, The Ohio State University, Columbus, $\mathrm{OH}$. 
Porter, E \& D. Williams. (1983). Review of The words you need. Reading in an Foreign Language, 1 (1), 68-71.

Reid, J. H. (1987). The learning style preferences of ESL students. TESOL Quarterly, 21 (1), 87-111.

Saunders, D. \& D. Crookall. (1985). Playing with a second language. Simulation/ Games for Learning, 15 (4), 166-172.

Shephard, R. (1967). Recognition memory for words, sentences, and pictures. Journal of Verbal Learning and Verbal Behavior, 6, 156-163.

Stahl, S. (1983). Differential word knowledge and reading comprehension. Journal of Reading Behavior, 15, 33-50.

Steiglitz, E. (1983). A practical approach to vocabulary reinforcement. English Language Teaching Journal, 37 (1), 71-76.

Stevick, E. (1976). Memory, meaning, and method. Rowley, MA: Newbury House.

Swaffar, J. K. (1988). Readers, texts, and second languages: The interactive processes. Modern Language Journal, 72 (2), 123-149.

Talbott, V. (1989). Personal communication, March 23.

Ur, P. (1984). Teaching listening comprehension. Cambridge: Cambridge University Press.

Van Buren, P. (1975). Semantics and language teaching. Papers in applied linguisncs. Ed. J. P. B. Allen \& S. P. Corder. London: Oxford University Press.

Wright, A. (1987). How to improve your mind. Cambridge: Cambridge University Press.

\section{THE AUTHORS}

Rebecca Oxford, professor of toreign language education and Russian at the University of Alabama, is the author of Language Learning Strategies: What Every Tearher Should Know and co-editor of Simulation, Gaming and Language Learning, both from Newbury House/Harper \& Row. She has a Ph.D. in educational psychology and two degrees in Russian and has directed intensive ESL at Pennsylvania State University.

David Crookall, professor in the MA TESL programme at the University of Alabama, is the primary editor of Simulation, Gaming and Language Learning (Newbury House) and several other books. His Ph.D. is from the University of Nancy II (France). He specializes in simulation and computer-assisted instruction and edits Simulation and Gaming: An International Journal of Theory, Design and Research (Sage). 